Vol 11, Issue 12, 2018

\title{
PROTEUS SYNDROME: NEED FOR PATIENT CENTRIC THERAPY
}

\section{GOWTHAMARAJAN KUPPUSAMY, ARUN RADHAKRISHNAN*, NIKHITHA K SHANMUKHAN, PRINEETHAA M, ANUSHA S}

Department of Pharmaceutics, JSS College of Pharmacy (Udhagamund), JSS Academy of Higher Education and Research, Mysuru, Karnataka, India. Email: arunpharma93@gmail.com

Received: 21 June 2018, Revised and Accepted: 30 July 2018

\section{ABSTRACT}

Proteus syndrome (PS) is a hamartomatous disorder with multisystem involvement that results from mutation in the AKT1gene. Since the symptoms and severity of PS are unique to each patient, diagnosis and treatment become hard for the physician. This article is concentrated upon the identification and recognition of specific characteristics of the disease, pathophysiology, symptoms, diagnosis, treatment and the necessity of advanced diagnosis, effective generalized and personalized therapy, as well as the requirement of new drugs for the management of PS. Detailed studies on the PS and evidence from the case reports revealed the requirement of intensive care, accurate diagnosis, and an effective treatment for each patient preferably patient-centric drug delivery due to the high degree of variation in the symptoms and clinical features among patients.

Keywords: Proteus syndrome, AKT1 gene, Pathophysiology, Symptoms, Diagnosis, Generalized and personalized treatment.

(C) 2018 The Authors. Published by Innovare Academic Sciences Pvt Ltd. This is an open access article under the CC BY license (http://creativecommons. org/licenses/by/4. 0/) DOI: http://dx.doi.org/10.22159/ajpcr.2018.v11i12. 28028

\section{INTRODUCTION}

Proteus syndrome (PS) is a hamartomatous disorder with multisystem involvement, resulting in excessive growth of body parts asymmetrically with high clinical variability due to the mosaic mutation in the AKT1 gene [1]. Complications of the disease may vary from benign and malignant tumors, skeletal malformations, blood vessel-associated abnormalities, bullous pulmonary disease, and certain skin lesions. Development of life-threatening conditions such as deep vein thrombosis and pulmonary embolism are prominent in PS [2]. PS stays silent in newborns and begins to exhibit the symptoms within 6-18 months and progresses with age. Irregularity in disease occurrence, inconsistency in symptoms among patients, restriction of the abnormal gene activity specifically to affected cells, presents challenges to physicians in diagnosis and treatment of PS [3]. Current diagnostic and treatment scenario in PS has been evaluated with the evidence of case reports and studies to recognize the challenges faced by the physicians during the diagnosis and treatment of the disease in different patients.

\section{HISTORY OF PS}

In the year 1983, a German Pediatrician Hans RudolfWiedemann named the disorder as PS, also called EllaProteus or elephant man disease. In 1979, Micheal Cohen explained the disorder to the community. The disorder was first identified in a patient named Merrick whose head was about 36 inches, one of his fingers was 5 inches, and the skin was covered with warty growths and smelled unpleasantly. He was studied by Treves and brought to the meeting of the pathological society in London for further studies. However, Merrick declined examinations and presentations. His figurative distortion until the end stage did not help in the diagnosis of the disease. Merrick died in the year of 1890 at the age of 27 due to suffocation caused by the weight of his head as he lied down [4]. In another case of a boy named Jordan 16-yearold, PS started affecting the fingers, spine, neck, and legs which became severe during the age of 14 . Above the knee amputation and the use of prosthetic legs has helped him in walking. Overgrowth of limbs, skin lesions, and thickening of the soles of his feet was precipitated by the disease [5]. In another case, a boy Sebastian from Australia presented distorted spine, bone overgrowth, orthopedic problems, and skin overgrowth [6]. The case of a 3 years and 8 months old girl with no family history of similar disorder demonstrated epidermal nevus, port-wine stains, macrodactyly with gigantism of feet, and swelling of abdomen and chest. During examination, she was observed with flat, soft, velvety, hyperpigmented linear nevus along the entire right arm extending to the neck, and then downward parallel to the midsignal line and a bluish red plague about 5 inches and 4 inches in size with an ill-defined border, studded with multiple, thick-walled, light- to dark-colored vesicles, and a few discharging serosanguinous fluids. PS gained wide public attention in the year 1980 after the movie called the elephant man $[7,8]$.

\section{EPIDEMIOLOGY}

PS is very rare with $<120$ individuals confirmed affected. 1 case/1,000,000 birth has a prevalence of PS. Males are more affected than females [9].

\section{PATHOPHYSIOLOGY}

PS is not caused by anything before or during pregnancy and not caused by any environmental exposure. The National Institute of Health $(\mathrm{NIH})$ has recently recognized that mutation in the gene called serine/ threonine kinase AKT1 causes PS. Alteration in AKT1 is "c. 49G>A, p.Glu17Lys," a "somatic-activating mutation." NIH studies revealed that the mutation occurs in particular cells and restricts itself to the affected cells and progeny. The overgrowth switches to malignancy in cells by signaling pathway of phosphatidylinositol 3 kinases (PI3K)/ AKT. AKT binds to phosphatidylinositol 3,4,5-trisphosphate, a second messenger through its Pleckstrin homology and translocates to the cell membrane, where it gets activated. Activation is through phosphorylation at the threonine 308 by phosphoinositide-dependent kinase 1. Phosphorylation of serine 473 completes the activation process with the help of mTORC2 complex. Stimulated growth factors induce phosphatidylinositol 3, which in turn increases the level of phosphatidylinositol 4,5-bisphosphate available for AKT activation. This will upregulate cell growth, proliferation, and downregulate apoptosis [10].

According to Lindhurst et al., AKT1 mutation is found only in the affected tissues, not in normal ones. PS is a result of somatic mutation, only cells which generate from the affected cells exhibit symptoms. Mutations in the 
developing phase have a less severe phenotype. The random nature of the somatic mutation exhibits in two components of PI3K signaling pathway, which makes PS a part of PTEN hamartoma tumor syndrome [11]. The diagrammatic representation of PS is given in Fig. 1.

\section{SYMPTOMS}

Symptoms and severity vary greatly from person to person. The peculiar characteristics of PS are the overgrowth of any tissue or organ in a mosaic and progressive manner. Asymmetric disproportionate growth of tissues causes distortion of the organ. Connective tissues, bones, fat, and skin have participated actively in PS. Cerebriform connective tissue nevi (CCTN), vascular anomalies, asymmetric overgrowth of bones, fatty tissue dysregulation, skin lesions with bumpy appearance, and scoliosis (curved spine) are prominently exhibited in PS [12]. Non-cancerous tumors often found in the ovarian membrane, malformation of the central nervous system (CNS) triggering mental disabilities, disfigurations such as a long face, narrow head, droopy eyelids, wide nostrils, and thickened skin pads on the soles of the feet are also identified in PS patients $[13,14]$. Most affected individuals are born without any noticeable symptoms. Overgrowth usually begins between 6 and 10 months. Brain overgrowth may be present at the time of birth [15]. Deep lines and overgrowth of soft tissues on the soles of the feet (cerebric form connective tissue moles on the skin) is a prominent symptom [16]. Medically, dangerous fat lipomas or invasive lipomas can produce large intrathoracic or intraabdominal lesions. Lymphatic malfunctions or port-wine stains can be generated by the abnormal blood or lymphatic vessels growth [17]. Internal organs affected are spleen and thymus, which become enlarged during disease progression. Learning disabilities, physical disfigurement, and developmental delays may also result from the AKT1 mutation. Affected individuals are prone to blood clots $[18,19]$. Predisposition to either benign or malignant tumors such as salivary gland tumors, monomorphic adenomas papillary thyroid carcinoma, breast cancer, and mesothelioma is more in PS. In some individuals, PS demonstrates its effect in almost all the organs as cystic lung disease, abnormalities of kidney or urinary system, and crossed eyes (benign eyeball cysts or tumors). Learning impairments and intelligence deficiency appears in specific patients $[20,21]$. The most life-threatening manifestations in PS are pulmonary embolism and deep vein thrombosis [22].

\section{CONSULTATION}

Multidisciplinary approach for consultation is advantageous over single physician advice. Orthopedist plays an important role in recognizing the functional significance of both hemihyperplasia and scoliosis. Cranial asymmetry otherwise known as hemifacial macrosomia can easily be identified by a craniofacial surgeon [23]. Furthermore, a plastic surgeon can do the resectioning of the cutaneous or subcutaneous lesions. CNS lesions, cortical overgrowth, hydrocephalus, craniofacial, and various surgical procedures can be addressed by a neurosurgeon with more accuracy. Successful evaluation of subcutaneous lesions and necessity of biopsies can be recognized by a dermatologist. Ocular involvement of the disease can be identified by an ophthalmologist. Dental anomalies can be treated by a dentist and malocclusion by an orthodontist. A geneticist can provide information regarding the diagnosis, diagnostic procedures, genetic mechanisms involved, and recurrence risks of the disease [24]. A pediatrician can evaluate the learning disabilities and developmental delays in a child and can include recommendations for therapy as well as schooling [25]

\section{DIAGNOSIS}

Physicians follow diagnostic criteria for the diagnosis of PS. The general criteria comprise of the identification of mosaic distribution (occurrence of overgrowth is restricted to the specific area of the body), sporadic occurrence, and progressive course of the disease [26]. The disease is confirmed when all three characteristics from general criteria, along with one manifestation from category A, two features from category B and three features from category C coexists. Specific criteria for the diagnosis of PS are mentioned in Table 1.

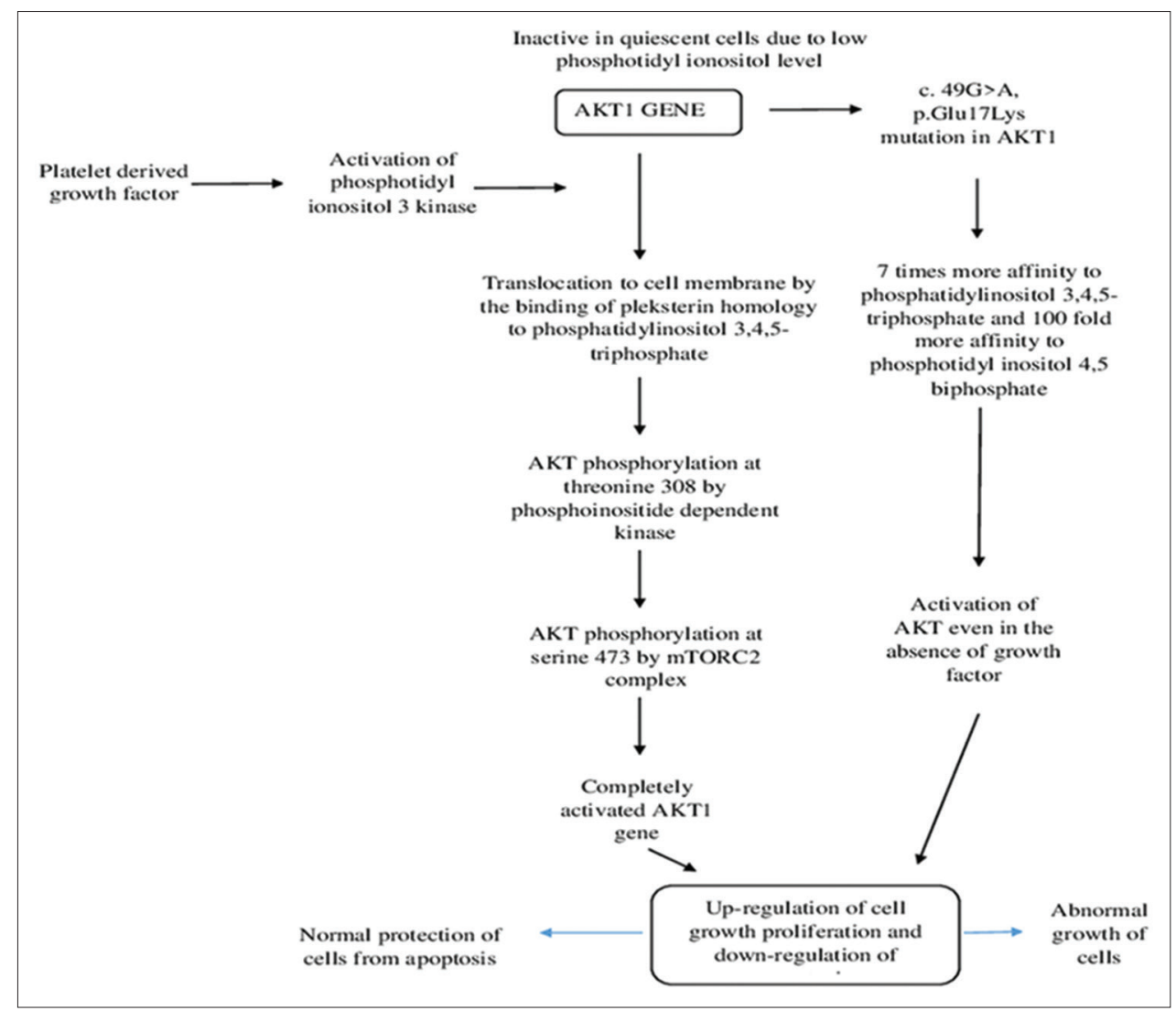

Fig. 1: Pathophysiology of Proteus syndrome 


\section{Differential diagnosis}

Differential diagnosis is the process of differentiating and confirming the presence of PS from similar disease conditions such as Maffucci syndrome, neurofibromatosis type 1 , Parkes-Weber syndrome, and encephalocraniocutaneous lipomatosis [27].

\section{Antenatal diagnosis}

Prenatal testing is not performed in most of the PS cases as PS is not inherited.

\section{Diagnostic tests in PS}

Molecular tests employed in the diagnosis of gene mutations in PS include targeted analysis to identify the c. $49 \mathrm{G}>\mathrm{A}$, p.Glu17Lys mutation. Analysis of multiple tissues, specifically punch biopsy of the affected area. Genomic testing is the more comprehensive analysis that comprises genome sequencing or exome sequencing. Invitae PS test is an example of the identification of AKT1 gene mutation. Other diagnostic techniques used are computed tomography scans, plain X-ray, high-resolution computed tomography (CT) scan of the lungs, brain, abdomen, limbs, and pelvis magnetic resonance imaging for ovarian masses detection $[28,29]$

\section{Case studies on diagnosis}

Skovby et al. (1993) studied two patients with spinal compromise in PS. In one of the patients, spinal stenosis resulted from an angular kyphoscoliosis, while in the second one, it resulted from infiltration of a paraspinal, intrathoracic angiolipoma [30].

Lacombe and Battin (1996) described two unrelated children diagnosed at birth with isolated macrodactyly. Examination showed the development of hemihypertrophy in both cases. The 4-year-old girl was observed with three dorsal angiomas. The symptoms of both of these patients fit the diagnostic criteria of PS [31].

De Becker et al. (2000) described a case on a 10-year-old boy with PS who presented pericardial effusion and hypogammaglobulinemia, with IgG and IgA deficiency and low levels of antibodies to pneumococcal and hemophilus type B polysaccharides, and lymphopenia. No cause was found for this immune deficiency, leading the authors to suggest that it may represent a hitherto unrecognized feature of PS [32].

Slavotinec (2000) reported three patients with PS who died suddenly from a pulmonary embolism. The first patient who was diagnosed with PS, at the age of 12 years, had varicose vein, portal vein thrombosis, right iliac vein occlusion, and recurrent pulmonary embolism. At the age 25, he died from pulmonary embolism. The second patient was a 9-year-old male who collapsed and died at home. An autopsy showed the cause of death as pulmonary embolism associated with deep vein thrombosis. The third case of a 17-year-old female showed a large pulmonary embolus with no identified deep vein thrombosis in autopsy when the sudden death happened during sinusitis treatment [33].

Mohamed bhai et al. (2002) administration of misoprostol combined prostaglandins was reported in mother with a baby having PS at 6 weeks' gestation in an attempt to abort the pregnancy [34].

Valéra et al. (2015) studied a case of a girl diagnosed with PS when she was 7. Even though fetal karyotyping was done during pregnancy stage, no abnormalities were found. During the age of three, she was examined by a neurologist because of a growth on her head and low language skills. Even though series of DNA studies for mutation was performed at different age levels, it was diagnosed as PS at the age of 7[35].

Rocha et al. (2017) reported a case of a 2-year-old boy diagnosed with PS. During the diagnosis, specific characteristics identified were macromelia of the limbs, syndactyly of the toes, and a wide gap between the toes. Prominent skin folding, irregular adipose tissue growth, and port-wine stains throughout the skin were seen. PS was diagnosed with abdomen ultrasound, Doppler echocardiography, Doppler ultrasound, and nuclear magnetic resonance of the skull [36].

\section{MANAGEMENT AND TREATMENT}

Physical and occupational therapy poses a major role in the treatment of PS. Designed orthotics such as special footwear may assist in walking. Rehabilitative medical care includes physical and occupational therapy such as correcting deformities of skeletal scoliosis. Orthopedic procedures help to delay or halt linear bone growth. Consideration of anticoagulant is a significant care, required in case of deep vein thrombosis or pulmonary embolism. A periodic examination can recognize the predisposition of tumors. Annual physical examination and radiography are also recommended [37]. Special care should be given to the dermatological abnormalities like CCTN with pedorthist intervention. Surgical removal of lesions is preferred if significant pain exists. The bullous pulmonary disease should be monitored continuously. Psychosocial counseling sessions are beneficial to the patient and family [38].

While considering the medicinal care, rapamycin in PS has found to have a positive potential. Another drug in Phase 1 is ARQ 092 inhibitor. The research has been performed by a team in the National Human Genome Research Institute at the US NIH [39]. Different treatments in PS are specified in Fig. 2.

\section{Generalized treatment \\ Medical care}

There is no approved drug for the treatment of PS. Existing treatments are only for the symptomatic relief of the disease. Rapamycin is a drug of choice in the treatment of PS which has been used as an effective immunosuppressant [40]. Mutation in the AKT1 gene provides an advantage of cell survival through phosphatidylinositol 3-kinase which is the target of rapamycin. Sirolimus-(FKBP-12) complex is inactive

Table 1: Specific criteria for the diagnosis of PS

\begin{tabular}{|c|c|c|c|c|c|}
\hline \multicolumn{2}{|l|}{ Category A } & \multicolumn{2}{|l|}{ Category B } & \multicolumn{2}{|l|}{ Category C } \\
\hline Common & Uncommon & Common & Uncommon & Common & Uncommon \\
\hline $\begin{array}{l}\text { Connective tissue } \\
\text { nevus }\end{array}$ & - & $\begin{array}{l}\text { 1. Epidermal nevus } \\
\text { 2. Disproportionate } \\
\text { overgrowth limbs } \\
\text { vertebrae } \\
\text { 3. Specific tumors before } \\
\text { the the end of the second } \\
\text { decade }\end{array}$ & $\begin{array}{l}\text { 2. Disproportionate } \\
\text { overgrowth skull } \\
\text { viscera } \\
\text { 3. Specific tumors } \\
\text { before the end of the } \\
\text { second decade bilateral } \\
\text { ovarian cystadenomas } \\
\text { Pleomorphic adenoma }\end{array}$ & $\begin{array}{l}\text { 1. Dysregulated } \\
\text { adipose tissues, } \\
\text { e.g., lipomas } \\
\text { 2. Vascular } \\
\text { malformation, } \\
\text { e.g., capillary } \\
\text { malformation, } \\
\text { venous and } \\
\text { lymphatic } \\
\text { malformation }\end{array}$ & $\begin{array}{l}\text { Facial phenotype, } \\
\text { e.g., long } \\
\text { face, open } \\
\text { mouth at rest, } \\
\text { dolichocephaly, } \\
\text { low nasal bridge }\end{array}$ \\
\hline
\end{tabular}

PS: Proteus syndrome 


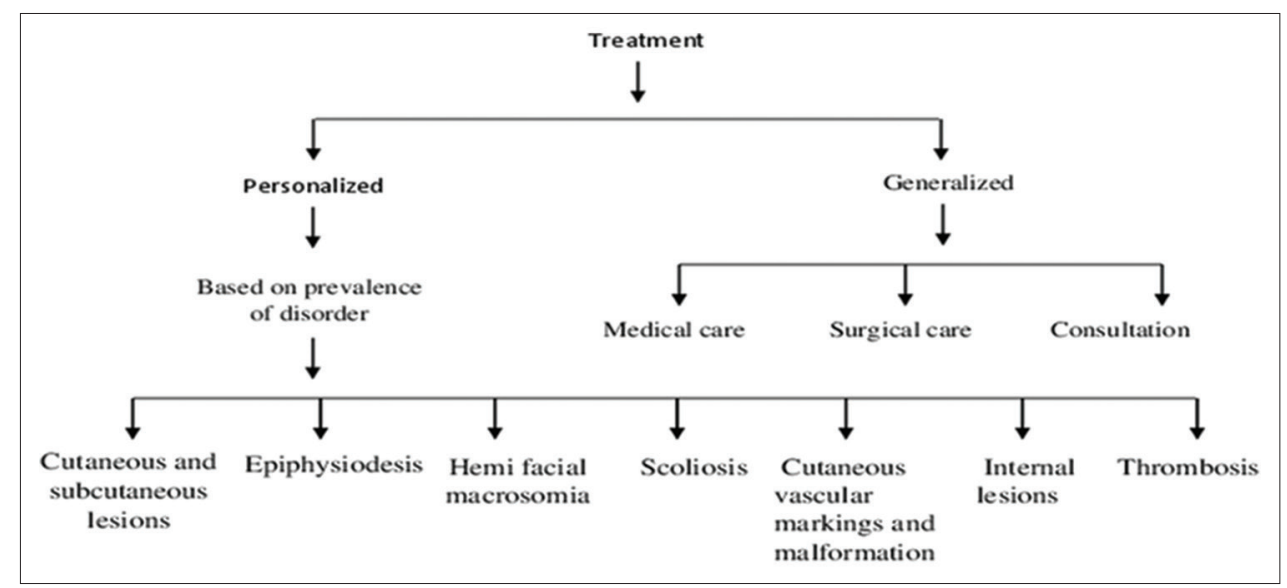

Fig. 2: Treatment of proteus syndrome

against calcineurin activity, the complex binds to the receptor and inhibits activation of a key regulatory kinase phosphatidylinositol 3-kinase (mTOR) in mammals. Inhibition of mTOR downregulates the activation of 4E binding protein 1 as well as ribosomal protein S6 [41].

Rapamycin is well absorbed from the gastrointestinal (GI) tract. 14\% Bioavailability with approximately $92 \%$ protein binding is exhibited by the drug. Attain $t_{\max }$ in 1-3 h, after oral administration. Peak blood concentrations of rapamycin were observed to be $12.2 \pm 6.2$ and $37.4 \pm 21 \mathrm{ng} / \mathrm{mL}$ in renal transplant patients administered $2 \mathrm{mg}$ and $5 \mathrm{mg}$, respectively, in combination with cyclosporine and corticosteroid. The major route of elimination is feces. The elimination half-life of sirolimus was found to be $62 \pm 16 \mathrm{~h}$ after multiple dosing in renal transplant patients. No information is available on the relationship of age to the effects of sirolimus. Rapamycin drug is a substrate for both cytochrome P-450, 3A4, and p-glycoprotein. Drug induction or inhibition can be produced by the substrates of these enzymes and transporter. Synergistic effect of rapamycin with cyclosporine can be avoided by administering rapamycin $4 \mathrm{~h}$ after administration of cyclosporine. Rapamycin tablets should be stored between $20^{\circ} \mathrm{C}$ and $25^{\circ} \mathrm{C}$ and oral solution should be stored between $2^{\circ} \mathrm{C}$ and $8{ }^{\circ} \mathrm{C}$ and protect from light [42].

Rapamycin may cause a serious viral infection of the brain that can lead to disability or death. Drug interactions or immunosuppression can worsen this condition. In case of any changes in mental state, problems with speech or walking, or decreased vision, consult with a doctor immediately because these symptoms may start and worsen quickly [43]. Mortality, graft rejection, and thrombosis in the hepatic artery are also reported in rapamycin administered patients. In liver transplanted and lung transplanted patients, drug can precipitate bronchial anastomotic dehiscence, hypersensitivity, dermatitis, angioedema, fluid accumulation along with wound healing impairment. Long-term administration can induce hypercholesteremia in patients.

Long-term rapamycin consumption increases insulin resistance. The research revealed both dietary restriction and rapamycin inhibited lipid synthesis which can cause insulin resistance. The drug metformin can effectively overcome the concern since it has been used in diabetic patients to encourage oxidation of lipid. The studies were performed in humans on the effectiveness of the metformin and rapamycin in the treatment of aging and age-associated diseases with the support of NIH. The case study was on a patient diagnosed with PS at 6 months of age. Treatment started with oral rapamycin at a low dose when he was 2 . The drug was found to be well tolerated and caused no side effects. Within 2 months of treatment, there was an increase in serum albumin level, and for 5 years, he was able to walk independently. After 17 months of therapy, the drug was ceased to check the reversible antitumor effect. 12 weeks of cessation lead to respiratory difficulties, but the biochemical evidence showed the resistance to growth hormone was not affected by rapamycin [44].

Even though drug therapy is not a part of standard PS care, studies by Lindhurst et al. suggested ARQ 092 as a drug for the disease. ARQ 092 is an orally active investigational drug producing its action by inhibiting AKT1, 2 and 3 isoforms. The drug is currently under clinical trial phase 1. According to the information provided by the National Institutes of Health Clinical Center, the dose of ARQ 092 was determined in vitro using the cell obtained from the PS patients' demonstrated reduced AKT1 phosphorylation with less toxicity. The study results hypothesize that the drug dose for the PS will be lesser than the dose of drug required for the cancer therapy since the aim of therapy is to inhibit the AKT signaling rather than killing the cells. The drug has also been studied for its effect on overgrowth diseases or vascular anomalies [45].

\section{Surgical care}

Surgical resectioning or even amputation is preferred in extreme circumstances. Prophylactic anticoagulation prior to elective surgery has been suggested by clinicians. For cosmetically important regions, plastic surgery is recommended. Subcutaneous lesions should be treated immediately once it starts to obstruct vision or impinging vital structures [46]. The size of the lipomatous lesions can be reduced employing laser lipolysis. This gives an advantage over surgical liposuction. Surgical resection may be helpful to prevent cystic lung malformations. The risk of the surgery includes the blood clot in veins, bleeding, adverse reaction to anesthesia, and overall risk of death [47]. Wenz and Berrsche studied different surgical cases of foot and ankle in PS. He has found that most of the surgical procedures such as osteotomies, soft-tissue resection, partial amputation, etc., were effective and patients were able to manage the normal functioning after surgery with the assistance of custom-made shoes [48].

\section{Personalized treatment}

The pattern of mutation in AKT1 gene, the cells affected by the mutation and the stage at which the mutation occurs determine the severity and the symptoms. The uniqueness of manifestations among the patients necessitates patient-centered therapy in PS. Early diagnosis of serious medical problems and the use of prophylactic and symptomatic treatment for functional improvement is the mainstay of PS. Epiphysiodesis may be especially useful to a patient with skeletal overgrowth. Medical approaches such as hemihyperplasia is limited to functional improvement. Macrodactyly impairs the normal functioning of hands and foot. Dental occlusion and mastication difficulties can be treated according to the patient concern. Hemifacial macrosomia or macroglossia is effective when cosmetic concerns of a patient are affected. Facial dysmorphism in a patient can be addressed by a maxillofacial surgeon or craniofacial team. Patients with lipomas and vascular malformations, postulate periodic evaluations throughout their life. Laser therapy is effective in the removal of cutaneous vascular 
markings and malformations. Permanent removal of melanin-related hyperpigmentation is not possible with laser therapy. Approaches comprising $\mathrm{CO}_{2}$ or ruby lasers, dermatome excision followed by phenol peel, cryotherapy, etc., are found to be effective in individual patients in various degrees. Management of thrombosis is an important consideration due to its life threating effects in patients with a palpable cord and respiratory distress. The risk of thrombosis is a major concern before surgery [4].

\section{RELATED DISORDERS OF PS}

Hemihyperplasia, a multiple lipomatosis syndrome, characterized by the formation of multiple tumors of fatty tissues and the abnormal enlargement of either sides of the body (asymmetrical growth). Hemihyperplasia may indicate asymmetry between one limb and another or between one half of the body and the other. Encephalocranio cutaneous lipomatosis is an extremely rare disorder characterized by eye and skin abnormalities inclu ding tumors of fatty tissues. Lipomatosis affects the scalp and central nervous system. Skin lesions consisting of abnormal connective tissues development are also manifested in encephalocranio cutaneous lipomatosis. Some individuals have normal intelligence while others may experience intellectual disability. Seizures and porencephalic cysts have also reported in several cases. Klippel-Trenaunay syndrome is identified by the presence of a capillary port wine stain on the skin with hypertrophy of the soft tissue, bone of that leg or arm. Maffucci syndrome, a PS related disorder characterized by benign cartilage overgrowths, skeletal deformities, and patches of skin as a result of cutaneous benign growths of blood vessels. Maffucci syndrome is inherited as an autosomal dominant trait [49-51].

\section{CASE REPORTS}

A case in China has been reviewed by Zhang et al. The case presents a 16-year-old girl with facial dysmorphism and verrucous hyperplasia on the right side of her body. She was deaf and exhibited more abnormalities as she grew. The physical examination unveils that she had a normal intelligence but several anomalies. CT scan of her head and face showed large lipomas. ECG and ultrasound for organs were normal [52].

Keerthi Talari, Praveenkumar, Arinaganhali, Subramanyam Dharanitragada Krishna presents a case of 50-year-old man with angina pain. They noticed the enlargement of his index and middle fingers of both hands and found that he had it from the age of 5. Hypertrophy of fingers limited normal functioning. His systemic examination was otherwise normal.

Article by Popescu et al. presented a case of a years old boy who has suffered from a disproportionate asymmetrical overgrowth of lower limbs, feet, right calf, and thigh. His facial phenotype was normal. In the anterior part of the calf, two hard masses were identified by ultrasound. Under general anesthesia, an excision of the fatty overgrowth and lymphangioma of the posterior part of the right calf were performed [53].

A report by $\mathrm{Ou}$ et al. was about a 34-year-old man in Europe. The patient was admitted to Shenzhen hospital for the treatment of postnasal overgrowth and skin problems in the limbs and hips. The affected tissue samples were collected from the patient for molecular biological analysis by whole-exome sequencing. Results were positive for PS. The patient refused surgery and treatment was given to control the skin and GI symptoms. Treatment included mupirocin for infection of skin lesions. Condition remained stable and the symptoms were partially controlled by the treatment [54].

A case report review by Satter presents a 19-year-old man from Nias Island in Indonesia. The patient had an enlargement of the left foot and vascular lesions on his left calf from the time of his birth but did not notice the foot size until it became thick and resulted in pain and difficulties in walking. Due to the vascular malformation, there was an increase in his foot growth at age 7. A plain lateral radiograph of foot confirmed the enlargement of bones.

Satter presents another case of a 10-year-old boy with vascular lesions on his right chest. During the examination, the physician observed asymmetrical enlargement on his chest and vascular malformation extended up to the upper abdomen and flank. In addition, cervical scoliosis and multiple large lipomas on his back were also identified [55].

This report done by Vasquez et al. presents a female patient from a third pregnancy. The girl was diagnosed with an abnormal size of inferior limbs and asymmetric finger growth at the month of 5 . She required amputation at a month of 12 . On clinical criteria of diagnosis, category A, a genetic study of two affected tissues were performed looking for mutation of AKT1 gene and the results were negative for AKT1 mutation. Ultrasound image showed a right solid paraovarian mass at 20 months of age when painless vaginal bleeding was noticed. The test was positive for tumor cells, but no other abnormal pathological findings were found. Post-operatory evolution was favorable and received three adjuvant chemotherapies in every 21 days for $3 \mathrm{~h}$. The patient was alive till 2 years with no evidence of disease [56].

Ference et al. studied a case on rehabilitation in PS where a 23-yearold female had a stable kyphoscoliosis amputation due to the large growth of both legs. She suffered from abnormal sensation, back and leg pain that disabled her from walking to a long distance. She was provided with the wheelchair for assistance. Her kyphoscoliosis was evaluated by an orthopedic spine surgeon. Even though non-surgical options such as shoe lifts to improve normal functioning are suggested, a patient with PS requires surgical procedures to minimize orthopedic deformities [57].

\section{CONCLUSION}

The absence of a specific pattern in the mutation in the AKT1 gene results in patient to patient variability in the disease symptoms. Difficulty in the identification of the mutated gene in the studies and the absence of proper diagnostic testing delay the confirmation of the disease at its early stages. This risk is especially great when the condition is polymorphous and variable in its expression and possibly falls under different medical disciplines. About 200 cases of PS have been reported in the literature, yet the incidence of symptoms like ocular malformations has not known. Under such circumstances, important single observations need to be reported and studied. Patientcentric therapy, care, and new drugs are required for the effective treatment of PS.

\section{REFERENCES}

1. Wieland I, Tinschert S, Zenker M. High-level somatic mosaicism of AKT1 c. $49 \mathrm{G}>$ A mutation in skin scrapings from epidermal nevi enables non-invasive molecular diagnosis in patients with Proteus syndrome. Am J Med Genet A 2013;161:889-91.

2. Parikh C, Janakiraman V, Wu WI, Foo CK, Kljavin NM, Chaudhuri S, et al. Disruption of PH-kinase domain interactions leads to oncogenic activation of AKT in human cancers. Proc Natl Acad Sci U S A 2012;109:19368-73.

3. Dalal AB, Phadke SR, Pradhan M, Sharda S. Hemihyperplasia syndromes. Indian J Pediatr 2006;73:609-15.

4. Cohen MM Jr., Hayden PW. A newly recognized hamartomatous syndrome. Birth Defects Orig Artic Ser 1979;15:291-6.

5. Gordon PL, Wilroy RS, Lasater OE, Cohen MM Jr. Neoplasms in Proteus syndrome. Am J Med Genet 1995;57:74-8.

6. Smith JM, Kirk EP, Theodosopoulos G, Marshall GM, Walker J, Rogers $\mathrm{M}$, et al. Germline mutation of the tumour suppressor PTEN in Proteus syndrome. J Med Genet 2002;39:937-40.

7. Harper J, Giehl K, Hennekam R. Proteus Syndrome. Harper's Textbook of Pediatric Dermatology, Volume 1, 2. $3^{\text {rd }}$ ed. Lou- Isiana, New Orleans: Butterworths; 1993. p. 111.

8. Sherzay N, Chitakar E. Epigenetics: Effect of environmental factors on human genome. Int J Pharm Pharm Sci 2016;8:1-6.

9. Proteus syndrome. Genetics home reference. Available from: https:// 
www.ghr.nlm.nih.gov/condition/proteus-syndrome\#statistics.

10. Yi KH, Lauring J. Recurrent AKT mutations in human cancers: Functional consequences and effects on drug sensitivity. Oncotarget 2016;7:4241-51.

11. Lindhurst MJ, Sapp JC, Teer JK, Johnston JJ, Finn EM, Peters K, et al. A mosaic activating mutation in AKT1 associated with the Proteus syndrome. N Engl J Med 2011;365:611-9.

12. Türk CY, Güney A, Oner M, Halıcı M. An unusual initial presentation of Proteus syndrome: Macrosyndactyly. Eklem Hastalik Cerrahisi 2011;22:56-9.

13. Beachkofsky TM, Sapp JC, Biesecker LG, Darling TN. Progressive overgrowth of the cerebriform connective tissue nevus in patients with Proteus syndrome. J Am Acad Dermatol 2010;63:799-804.

14. Hagari Y, Aso M, Shimao S, Okano T, Kurimasa A, Takeshita K, et al. Proteus syndrome: Report of the first Japanese case with special reference to differentiation from Klippel-trenaunay-weber syndrome. J Dermatol 1992;19:477-80.

15. Rodenbeck DL, Greyling LA, Anderson JH, Davis LS. Early recognition of Proteus syndrome. Pediatr Dermatol 2016;33:e306-10

16. Happle R. The manifold faces of Proteus syndrome. Arch Dermatol 2004;140:1001-2.

17. Martínez-Glez V, Romanelli V, Mori MA, Gracia R, Segovia M, González-Meneses A, et al. Macrocephaly-capillary malformation: Analysis of 13 patients and review of the diagnostic criteria. Am J Med Genet A 2010;152A:3101-6.

18. Asilian A, Kamali AS, Riahi NT, Adibi N, Mokhtari F. Proteus syndrome with arteriovenous malformation. Adv Biomed Res 2017;6:27.

19. Biesecker LG, Happle R, Mulliken JB, Weksberg R, Graham JM Jr., Viljoen DL, et al. Proteus syndrome: Diagnostic criteria, differential diagnosis, and patient evaluation. Am J Med Genet 1999;84:389-95

20. Nerkar DA, Mukherjee AN, Mehta BK, Banerjee SU. Metabolic syndrome associated complications. Int J Pharm Pharm Sci 2015;7:22-5.

21. Romano C, Schepis C. PTEN gene: A model for genetic diseases in dermatology. Sci World J 2012;2012:252457.

22. Elsayes KM, Menias CO, Dillman JR, Platt JF, Willatt JM, Heiken JP, et al. Vascular malformation and hemangiomatosis syndromes: Spectrum of imaging manifestations. AJR Am J Roentgenol 2008;190:1291-9.

23. Cohen MM Jr., Proteus syndrome review: Molecular, clinical, and pathologic features. Clin Genet 2014;85:111-9.

24. Cohen MM. Proteus syndrome: An update. Am J Med Genet Part C: Semin Med Genet 2005;137:38-52

25. Barry M, Wilson WG. Proteus Syndrome Treatment and Management. U.S: Medscape; 2016.

26. Adams DM, Trenor CC $3^{\text {rd }}$, Hammill AM, Vinks AA, Patel MN, Chaudry G, et al. Efficacy and safety of sirolimus in the treatment of complicated vascular anomalies. Pediatrics 2016;137:e20153257.

27. Biesecker LG. The multifaceted challenges of Proteus syndrome. JAMA 2001;285:2240-3

28. Loffeld A, McLellan NJ, Cole T, Moss C. Type 2 segmental Cowden disease vs. Proteus syndrome: Reply from authors. Br J Dermatol 2008;158:410-1.

29. Gilbert-Barness E, Cohen MM Jr., Opitz JM. Multiple meningiomas, craniofacial hyperostosis and retinal abnormalities in Proteus syndrome. Am J Med Genet 2000;93:234-40.

30. Skovby F, Graham JM Jr. Sonne-Holm S, Cohen MM Jr. Compromise of the spinal canal in Proteus syndrome. Am J Med Genet 1993;47:656-9.

31. Lacombe D, Battin J. Isolated macrodactyly and Proteus syndrome. Clin Dysmorphol 1996;5:255-7.

32. De Becker I, Gajda DJ, Gilbert-Barness E, Cohen MM Jr. Ocular manifestations in Proteus syndrome. Am J Med Genet 2000;92:350-2.

33. Slavotinek AM, Vacha SJ, Peters KF, Biesecker LG. Sudden death caused by pulmonary thromboembolism in Proteus syndrome. Clin Genet 2000:58:386-9.

34. Mohamedbhai AG, Hassan Miyan AM, Lacombe D. Neonatal Proteus syndrome? Am J Med Genet 2002;112:228-30.

35. Valéra MC, Vaysse F, Bieth E, Longy M, Cances C, Bailleul-Forestier I, et al. Proteus syndrome: Report of a case with AKT1 mutation in a dental cyst. Eur J Med Genet 2015;58:300-4.

36. Rocha RC, Estrella MP, Amaral DMD, Barbosa AM, Abreu MA. Proteus syndrome. An Bras Dermatol 2017;92:717-20.

37. Peters KF, Biesecker LG. An opportunity for genetic counseling intervention: Depression in parents of individuals with Proteus syndrome. J Genet Couns 2000;9:161-71.

38. Batra P, Duggal R, Parkash H. Craniofacial and dental manifestations of a case of proteus syndrome. J Indian Soc Pedod Prev Dent 2004;22:154-7.

39. National Institutes of Health Clinical Center. Dose Finding Study of ARQ092 in Childrens and Adults with Proteus Syndrome. U.S: National Institutes of Health Clinical Center (CC).

40. Reza MI, Goel D, Rahman Z, Aamer S. Microrna and RNA binding proteins: The posttranscriptional regulators of foxo expression. J Crit Rev 2018;5:1-9.

41. Marsh DJ, Trahair TN, Martin JL, Chee WY, Walker J, Kirk EP, et al. Rapamycin treatment for a child with germline PTEN mutation. Nat Clin Pract Oncol 2008;5:357-61.

42. Suzuki Y, Enokido Y, Yamada K, Inaba M, Kuwata K, Hanada N, et al. The effect of rapamycin, NVP-BEZ235, aspirin, and metformin on $\mathrm{PI} 3 \mathrm{~K} / \mathrm{AKT} / \mathrm{mTOR}$ signaling pathway of PIK3CA-related overgrowth spectrum (PROS). Oncotarget 2017;8:45470-83.

43. Sene LS, Sales PD, Chojniak R. Proteus syndrome: Case report. Revista da Associação Médica Brasileira 2013;59:318-20.

44. Barzilai N, Crandall JP, Kritchevsky SB, Espeland MA. Metformin as a tool to target aging. Cell Metab 2016;23:1060-5.

45. Lindhurst MJ, Yourick MR, Yu Y, Savage RE, Ferrari D, Biesecker LG, et al. Repression of AKT signaling by ARQ 092 in cells and tissues from patients with proteus syndrome. Sci Rep 2015;5:17162.

46. Lublin M, Schwartzentruber DJ, Lukish J, Chester C, Biesecker LG, Newman KD, et al. Principles for the surgical management of patients with Proteus syndrome and patients with overgrowth not meeting proteus criteria. J Pediatr Surg 2002;37:1013-20.

47. Bunker JP. Surgical manpower. A comparison of operations and surgeons in the United States and in England and Wales. N Engl J Med 1970;282:135-44.

48. Wenz W, Berrsche G. Proteus syndrome: Surgical treatment in foot and ankle. Tech Foot Ankle Surg 2014;13:206-11.

49. Cassidy SB, McCandless SE. In: Cassidy SB, Allanson JE, editors. Prader-Willi Syndrome In: Management of Genetic Syndromes. New York: John Wiley and Sons; 2005. p. 429-48.

50. Biesecker L. Proteus Syndrome. NORD Guide to Rare Disorders. Philadelphia, PA: Lippincott Williams and Wilkins; 2003. p. 239.

51. Devi S, Singh K. Risk factors, prevalence and diagnosis of Hutchison gilford syndrome with special reference to case reports. J Pharm Pharm Sci 2016;915:16282.

52. Zhang XB, Li CX, He YQ, Zhang SQ, Cai YX. Proteus syndrome: A case report and a case study review in china. Dermatol Reports 2010;2:e3.

53. Popescu MD, Burnei G, Draghici L, Draghici I. Proteus syndrome: A difficult diagnosis and management plan. J Med Life 2014;7:563-6.

54. Ou M, Sun Z, Zhu P, Sun G, Dai Y. Proteus syndrome: A case report and review of the literature. Mol Clin Oncol 2017;6:381-3.

55. Satter E. Proteus syndrome: 2 case reports and a review of the literature. Cutis 2007;80:297-302.

56. Vasquez L, Tello M, Maza I, Oscanoa M, Dueñas M, Castro H, et al. Endometrioid paraovarian borderline cystic tumor in an infant with Proteus syndrome. Case Rep Oncol Med 2015;2015:392576.

57. Ference T, Fertig RM, Feldman M, Jacobs J, Casella G, Mena J. Rehabilitation of a patient with Proteus syndrome case report and literature review. J Clin Med Ther 2017;2:16. 